\title{
Vacuum-ultraviolet (VUV) photoionization of small methanol and methanol-water clusters
}

\begin{tabular}{|r|l|}
\hline Journal: & The Journal of Physical Chemistry \\
\hline Manuscript ID: & jp-2008-020479.R1 \\
\hline Manuscript Type: & Special Issue Article \\
\hline Author: & $\mathrm{n} / \mathrm{a}$ \\
\hline Complete List of Authors: & $\begin{array}{l}\text { Kostko, Oleg; LBNL } \\
\text { Belau, Leonid; LBNL } \\
\text { Wilson, Kevin; LBNL } \\
\text { Ahmed, Musahid; Lawrence Berkeley National Laboratory, Chemical } \\
\text { Sciences Division }\end{array}$ \\
\hline
\end{tabular}

\section{S ScholaronE \\ Manuscript Central}




\author{
Vacuum-ultraviolet (VUV) photoionization of small methanol and methanol-water clusters \\ Oleg Kostko, Leonid Belau, Kevin R. Wilson, and Musahid Ahmed* \\ Chemical Sciences Division, Lawrence Berkeley National Laboratory, \\ Berkeley, CA-94720, USA
}

\begin{abstract}
In this work we report on the vacuum-ultraviolet (VUV) photoionization of small methanol and methanol-water clusters. Clusters of methanol with water are generated via co-expansion of the gas phase constituents in a continuous supersonic jet expansion of methanol and water seeded in Ar. The resulting clusters are investigated by single photon ionization with tunable vacuumultraviolet synchrotron radiation and mass analyzed using reflectron mass spectrometry. Protonated methanol clusters of the form $\left(\mathrm{CH}_{3} \mathrm{OH}\right)_{n} \mathrm{H}^{+}(\mathrm{n}=1-12)$ dominate the mass spectrum below the ionization energy of the methanol monomer. With an increase in water concentration, small amounts of mixed clusters of the form $\left(\mathrm{CH}_{3} \mathrm{OH}\right)_{n}\left(\mathrm{H}_{2} \mathrm{O}\right) \mathrm{H}^{+}(\mathrm{n}=2-11)$ are detected. The only unprotonated species observed in this work are the methanol monomer and dimer. Appearance energies are obtained from the photoionization efficiency (PIE) curves for $\mathrm{CH}_{3} \mathrm{OH}^{+},\left(\mathrm{CH}_{3} \mathrm{OH}\right)_{2}{ }^{+}$, $\left(\mathrm{CH}_{3} \mathrm{OH}\right)_{n} \mathrm{H}^{+}(\mathrm{n}=1-9)$, and $\left(\mathrm{CH}_{3} \mathrm{OH}\right)_{n}\left(\mathrm{H}_{2} \mathrm{O}\right) \mathrm{H}^{+}(\mathrm{n}=2-9)$ as a function of photon energy. With an increase in the water content in the molecular beam, there is an enhancement of photoionization intensity for methanol dimer and protonated methanol monomer at threshold. These results are compared and contrasted to previous experimental observations.
\end{abstract}

\footnotetext{
* MS: 6R-2100, Lawrence Berkeley National Laboratory, 1 Cyclotron Road, Berkeley, CA94720, USA. Phone: (510) 486-6355; fax: (510) 486-5311; e-mail: MAhmed@lbl.gov
} 


\section{Introduction}

Photoionization studies of hydrogen bonded clusters provide insight into the thermodynamic and bonding properties of these systems. There have been numerous studies of methanol and methanol-water clusters utilizing a variety of ionization schemes. ${ }^{1-10}$ Initial work has focused on ion molecule reactions within these clusters upon photoionization. Recently there has been a resurgence in the number of fundamental studies of hydrogen bonded clusters, ${ }^{11}$ arising from the importance that these systems play in the astrochemical processing of hydrocarbons, ${ }^{12}$ and local structure of mixed liquids. ${ }^{13}$ The photoionization properties of alcoholwater clusters is also important in the analytical chemistry community. ${ }^{14}$ Frequently methanol is used as a dopant to facilitate ionization in atmospheric pressure photoionization. It is believed that the addition of methanol leads to cluster formation and a lowering of the ionization energy of the system. ${ }^{14}$

Recently we have initiated a program to study the photoionization dynamics of hydrogen bonded systems upon vacuum-ultraviolet irradiation. Measurements of photoionization onsets and mass spectra afford a window to deciphering fragmentation mechanisms and thermodynamic properties that have hitherto not been possible. While there have been a plethora of experimental work on methanol and mixed methanol-water clusters, there are certain outstanding questions remaining. The appearance of magic numbers, i.e. cluster ions with enhanced intensities compared to neighboring masses, and the formation of mixed methanol-water cluster ions from pure methanol upon ionization have led to much debate in the literature. ${ }^{15}$ The fragmentation of these fragile hydrogen bonded clusters upon ionization has been studied in detail. However the difference in proton transfer mechanisms of the two different hydrogens in methanol, e.g. the hydrogens bonded to the methyl group and to oxygen, remains ambiguous. This would make the 
ionization of methanol different from water, where there are two equivalent hydrogens. The changes in ionization properties upon clustering also allows for systematic trends to be studied utilizing tunable sources of ionization

In a very early study, Kebarle and co-workers irradiated water-methanol vapor mixtures with an $100 \mathrm{keV}$ proton beam in a high pressure mass spectrometer. ${ }^{2}$ They observed series of clusters comprised of $\left(\mathrm{CH}_{3} \mathrm{OH}\right)_{\mathrm{m}}\left(\mathrm{H}_{2} \mathrm{O}\right)_{\mathrm{n}} \mathrm{H}^{+}$where methanol is taken up preferentially in clusters of small size and water for the large ones $(m+n>9)$. They suggested that the proton is preferentially solvated by water in mixed water-methanol solutions. Stace and Shukla ${ }^{6}$ performed electron-impact ionization of mixed water-methanol clusters generated in an adiabatic expansion and observed a similar series of protonated clusters of the formula $\left(\mathrm{CH}_{3} \mathrm{OH}\right)_{\mathrm{m}}\left(\mathrm{H}_{2} \mathrm{O}\right)_{n} \mathrm{H}^{+}$up to $\mathrm{m}+\mathrm{n}<25$. Analysis of the metastable peak intensities showed that the proton is preferentially attached to methanol up to $n=9$ and then it switches over to water. This result suggests that upon ionization, neutral water elimination is the predominant loss channel for small cluster ions while larger cluster ions decompose by losing an alcohol. These results were explained by invoking the strength of ion-dipole interactions and the polarizability of the water-methanol clusters.

A very detailed study of mixed water-alcohol clusters to probe the structure and reactivity of these hydrogen bonded systems was performed by Garvey and co-workers ${ }^{15}$. For methanol, they observed protonated methanol clusters complexed with one and two water molecules. They also observed enhanced stability (magic number) for $\left(\mathrm{CH}_{3} \mathrm{OH}\right)_{9}\left(\mathrm{H}_{2} \mathrm{O}\right) \mathrm{H}^{+}$and $\left(\mathrm{CH}_{3} \mathrm{OH}\right)_{10}\left(\mathrm{H}_{2} \mathrm{O}\right)_{2} \mathrm{H}^{+}$. Similar behavior was observed for water clustered with ethanol, 1- and 2propanol as well as neat alcohol clusters. For pure alcohol, they concluded that the water component observed in the cluster ions of neat alcohol was produced by intra-cluster ionmolecule reactions. Castleman and co-workers ${ }^{4}$ observed similar behavior for 
$\left(\mathrm{CH}_{3} \mathrm{OH}\right)_{\mathrm{m}}\left(\mathrm{H}_{2} \mathrm{O}\right) \mathrm{H}^{+}(\mathrm{m} \geq 7)$ upon multiphoton ionization of neat methanol clusters.

Thermodynamic stability of intermediate cluster structures followed by proton transfer was suggested to give rise to the observed distribution. The similarity of observed cluster ion distributions formed from both neat alcohol and mixed methanol-water clusters suggests that it is the stability of the ion products that dictates the final cluster ion distribution rather than the initial composition of the neutral beam. ${ }^{15}$ In other words, in the case of methanol, ion-molecule reactions within the photoionized clusters leads to the formation of mixed clusters of the form $\left(\mathrm{CH}_{3} \mathrm{OH}\right)_{\mathrm{m}}\left(\mathrm{H}_{2} \mathrm{O}\right)_{\mathrm{n}} \mathrm{H}^{+}$from a neat methanol cluster beam.

Castleman and co-workers ${ }^{16}$ very early on also showed that mixed water-methanol cluster ions give rise to magic numbers for structures $\left(\mathrm{CH}_{3} \mathrm{OH}\right)_{m}\left(\mathrm{H}_{2} \mathrm{O}\right)_{n} \mathrm{H}^{+}$at $m+n=21,0 \leq \mathrm{m} \leq 8$ due to the enhanced stability of the dodecahedral cage structure in the mixed clusters. Fixed frequency VUV lasers, at $10.5 \mathrm{eV}^{10,17}$ and $26.5 \mathrm{eV}^{18}$ have been used to single photon ionize methanol cluster beams. Shi et al. ${ }^{10}$ claimed that the protonated trimer is the most intense peak (magic number), protonated clusters being observed up to the pentamer. The authors attempted to correlate the measured ion distribution to the neutral cluster population. In contrast to the results at $10.5 \mathrm{eV}$, photoionization at $26.5 \mathrm{eV}$ gives rise to the protonated dimer as the most dominant and protonated clusters $\left(\mathrm{CH}_{3} \mathrm{OH}\right)_{\mathrm{n}} \mathrm{H}^{+}$are detected up to $\mathrm{n}=10$. The authors argued that the depletion in the dimer signal in the $10.5 \mathrm{eV}$ experiments is due to a near threshold ionization of the trimer at this wavelength leading to a reduced cross-section for ionization. It is important to point out that these cross-sections are unknown. In the same work, the authors state that the excess energy available is removed by the departing electron.

Nishi and Yamamoto ${ }^{7}$ created mixed clusters of a number of molecules with water by adiabatic expansion of liquid jets into vacuum. The resulting cluster beams were electron-impact 
ionized and quantitatively analyzed using mass spectrometry, which allowed for the determination of the stability of the hydrated clusters. They found that the cluster ions, produced by this method provides a signature of the neutral cluster distribution and also to the structure of the original liquid solution itself. Following on from this work, Wakisaka et al. ${ }^{19}$ performed mass spectrometry of binary mixtures to explore non-ideal mixing. They found that methanol added to water leads to a substitution mechanism, i.e. water molecules are progressively replaced by methanol in the hydrogen bonded structures. Raina and Kulkarni, ${ }^{13}$ also suggest that the ion cluster distribution of methanol-water mixtures provides information about the neutral binary vapor, which in turn reflects the structure of the liquid itself.

A major factor in utilizing soft ionization techniques that is provided by VUV light is to be able to decipher ionization mechanisms. The absence of unprotonated clusters in the mass spectrum upon photoionization is one of the most striking observations in the mass spectrometry of hydrogen bonded clusters. It is suggested that proton transfer reactions are very efficient within the ionized clusters and that the vertical ionization threshold leading to direct formation of unprotonated species is probably higher than the barrier to proton transfer. Systematic studies with tunable VUV light should shed light on these relative thresholds and fragmentation pathways. Early work by Cook et al. ${ }^{1}$ utilized the University of Wisconsin synchrotron to photoionize an alcohol cluster beam. Appearance energies (shown in brackets in $\mathrm{eV}$ ) for $\mathrm{CH}_{3} \mathrm{OH}^{+}$(10.84), $\left(\mathrm{CH}_{3} \mathrm{OH}\right) \mathrm{H}^{+}(10.2),\left(\mathrm{CH}_{3} \mathrm{OH}\right)_{2} \mathrm{H}^{+}$(9.8), $\left(\mathrm{CH}_{3} \mathrm{OH}\right)_{3} \mathrm{H}^{+}(9.5),\left(\mathrm{CH}_{3} \mathrm{OH}\right)_{4} \mathrm{H}^{+}(9.3)$ were reported in that work. The authors did not observe any unprotonated clusters. From the dependence of cluster ion intensities on source conditions, estimates were provided for the heats of formation for methanol clusters. 
Booze and Baer $^{20}$ utilizing coincidence techniques in conjunction with synchrotron radiation reported detecting $\left(\mathrm{CH}_{3} \mathrm{OH}\right)_{2}{ }^{+}$at $10.2 \mathrm{eV}$ photon energy. By comparing peak intensities and widths of the protonated dimer $\left(\mathrm{CH}_{3} \mathrm{OH}\right)_{2} \mathrm{H}^{+}$with $\left(\mathrm{CH}_{3} \mathrm{OH}\right)_{2}{ }^{+}$, they concluded that dissociative photoionization gave rise to the protonated dimer. Tomoda and Kumara $^{21}$ utilizing He I radiation, reported the vertical ionization energy of the methanol dimer $\left(\left(\mathrm{CH}_{3} \mathrm{OH}\right)_{2}\right)$ to be $10.4 \mathrm{eV}$. Martrenchard et al. ${ }^{22}$ studied the proton transfer mechanism by performing threshold coincidence measurements with VUV radiation. They report a vertical ionization energy of $9.7 \pm 0.05 \mathrm{eV}$ for $\left(\mathrm{CH}_{3} \mathrm{OH}\right)_{2}{ }^{+}$and the appearance energy for the protonated methanol ion $\left(\mathrm{CH}_{3} \mathrm{OH}\right) \mathrm{H}^{+}$to be $10.15 \pm 0.05 \mathrm{eV}$. By performing isotopic and threshold ionization studies, the authors surmised that two proton transfer mechanisms take place - one involves the methyl group which is exothermic but with a barrier, and the proton transfer from the hydroxyl group occurs at threshold without a barrier. Lee et al. ${ }^{23}$ have performed extensive mass spectrometric and molecular orbital studies of electron impact ionized methanol clusters with particular emphasis on the methanol dimer. They proposed that ion-neutral complexes of the type $\left[\mathrm{CH}_{3} \mathrm{OH}_{2}{ }^{+} \cdots \mathrm{O}(\mathrm{H}) \mathrm{CH}_{2}\right]$ and $\left[\mathrm{CH}_{3} \mathrm{OH}_{2}{ }^{+} \cdots \mathrm{OCH}_{3}\right]$ lead to the formation of the protonated species $\mathrm{CH}_{3} \mathrm{OH}_{2}{ }^{+}$with concomitant elimination of $\mathrm{CH}_{2} \mathrm{OH}$ and $\mathrm{OCH}_{3}$ respectively. However, the calculated barriers and thresholds do not agree qualitatively with the results of Martrenchard et al. ${ }^{22}$ Tsai et al. ${ }^{24}$ photoionized the methanol dimer using a tunable VUV laser in conjunction with deuteration studies and also performed extensive $a b$-initio calculations to get a handle on the mechanism of proton transfer in this system. In the range of $10.49-10.9 \mathrm{eV}$, the probability of the proton transfer from the hydroxyl group increased with photon energy. Using ab-initio methods, the authors found four stable structures of the methanol dimer, one of these $\left[\mathrm{CD}_{3} \mathrm{OHD}^{+}\right.$ $\left.\cdots \mathrm{CD}_{2} \mathrm{OH}\right]$ is supposed to play a major role in the deuteron transfer reaction. The reported energy 
barriers and pathways to proton and deuteron transfer from the methanol dimer is at variance from those calculated earlier by Lee et al. ${ }^{23}$

We have performed a systematic study utilizing tunable VUV in conjunction with reflectron mass spectrometry to shed light on some of the outstanding questions that remain on photoionization mechanism of hydrogen bonded clusters of methanol and methanol with water. The variation in intensities of mass spectral peaks with the addition of water to methanol at various photon energies is discussed and contrasted with previous work. We will show that photoionization mass spectrometry under our clustering conditions does not reflect the composition of the original liquid solution. Appearance energies for a number of protonated methanol and methanol-water clusters are reported for the first time.

\section{Experimental}

The experiments are performed in a chamber incorporating a continuous supersonic expansion of methanol and methanol-water mixtures to produce clusters. The apparatus is coupled to a three meter vacuum ultraviolet monochromator on the Chemical Dynamics Beamline (9.0.2) located at the Advanced Light Source. This apparatus is recently discussed for generating pure water clusters ${ }^{25}$ and relatively minor changes are introduced, such as to produce a continuous supersonic molecular beam of mixed methanol-water clusters. Neutral clusters are formed in a supersonic expansion of $114 \mathrm{kPa}$ of Ar with seeded methanol and methanol-water vapor through a $100 \mu \mathrm{m}$ nozzle orifice and pass through a $1 \mathrm{~mm}$ conical skimmer located $20 \mathrm{~mm}$ downstream. Ar is passed through a bubbler containing either pure methanol liquid or methanolwater mixtures. Methanol with purity higher than $99.8 \%$ and deionized water are used for preparation of samples. The pressures in the source and main chambers are $4.2 \times 10^{-2} \mathrm{~Pa}$ and $2.4 \times 10^{-4} \mathrm{~Pa}$, under normal operating conditions. 
In the main chamber, the neutral cluster beam is interrogated in the ionization region of a commercial reflectron time-of-flight (TOF) mass spectrometer by tunable VUV radiation. Since the synchrotron light is quasi-continuous $(500 \mathrm{MHz})$, a start pulse for the TOF ion packet is provided by pulsing the ion optics electric potential. The accelerator and repeller plates of the ion optics are biased at the same potential $(1600 \mathrm{~V})$, and ions are extracted by fast switching of the repeller plate to $1900 \mathrm{~V}$ with a pulse width of $2.5 \mu$ s. Ions are accelerated perpendicularly to their initial velocity direction through the field free region towards the reflectron. Ions, reflected in the electrostatic field of the ion mirror, are detected by a microchannel plate (MCP) installed at the end of the second field free region. The time-dependent electrical signal from the MCP is amplified by a fast preamplifier, collected by a multichannel-scalar card and thereafter integrated with a PC computer. Time-of-flight spectra are recorded for the photon energy range between 9 and $15 \mathrm{eV}$. The typical photon energy step size used for these experiments is $50 \mathrm{meV}$ and the accumulation time at each photon energy is $300 \mathrm{~s}$. The photoionization efficiency curves of the clusters are obtained by integrating over the peaks in the mass spectrum at each photon energy and normalized by the photon flux. The synchrotron VUV photon flux is measured by a Si photodiode. Argon absorption lines are used for energy calibration of the PIE spectra.

\section{Results and Discussion}

\section{Mass Spectrometry of methanol clusters}

Mass spectra of neat methanol and methanol-water mixtures were collected between photon energies of 9 and $15 \mathrm{eV}$. Fig. 1 shows a mass spectrum of a supersonic expansion of the vapor above a 5:1 by volume methanol-water solution recorded with a photon energy of $11 \mathrm{eV}$. The methanol monomer $(\mathrm{IE}=10.8 \mathrm{eV})$, dominates the mass spectrum followed by protonated methanol clusters $\left(\left(\mathrm{CH}_{3} \mathrm{OH}\right)_{n} \mathrm{H}^{+}\right)$. In addition a weak series composed of $\left(\mathrm{CH}_{3} \mathrm{OH}\right)_{n}\left(\mathrm{H}_{2} \mathrm{O}\right) \mathrm{H}^{+}$is 
also observed. A peak at $\mathrm{m} / \mathrm{z}=64$ (not shown in the figure) is assigned to the methanol dimer $\left(\mathrm{CH}_{3} \mathrm{OH}\right)_{2}{ }^{+}$, this being the only unprotonated cluster apart from parent methanol and water being detected. The absence of unprotonated cluster peaks arises from the instability of the ionized clusters and efficient proton transfer that occurs upon photoionization even at threshold energies.

There has been reports in the literature, ${ }^{13,26}$ that molecular beam mass spectrometry allows for determination of the bonding properties of mixtures. In other words, the local structure of mixed liquid systems is retained in memory upon being ionized in a molecular beam. These experiments are different from the adiabatic expansion of liquid jets as has been practiced by Nishi and co-workers ${ }^{7}$ where it is possible to sample directly from the liquid. We used tabulated values $^{27}$ of vapor phase constituents of methanol-water solutions to calculate the mole fraction of methanol vapor in the reservoir containing the solution. The methanol-water volume mixing ratios of $50: 1,10: 1,5: 1,1: 1$, and $1: 2$ in solution correspond to a methanol vapor mole fraction of $0.99,0.94,0.90,0.72$, and 0.59 respectively. These values correlate in a linear manner with the detected water /methanol monomer ratio shown in Fig. 2. This plot provides evidence that in our experiments we are entraining the vapor component of the mixture in the carrier gas, and subsequent cluster formation takes place upon supersonic expansion from the nozzle. This would suggest that in our experimental configuration we are only sensitive to the vapor component above the liquid solution. The fact that we observe clusters in our supersonic expansion suggests significant cooling is being provided in the molecular beam.

The peak intensities of protonated methanol and methanol-water clusters recorded under methanol vapor mole fraction of $0.99,0.94,0.90,0.72$, and 0.59 at photon energies of 10 and 12 $\mathrm{eV}$ are shown in Fig. 3. The cluster ion distributions have been normalized to the protonated 
methanol monomer intensity recorded at $12 \mathrm{eV}$ to allow for a comparison of systematic trends upon increased water concentration in the solution.

In the protonated methanol cluster series recorded at $10 \mathrm{eV}$ (Fig. $3 \mathrm{a}),\left(\mathrm{CH}_{3} \mathrm{OH}\right)_{4} \mathrm{H}^{+}$is the most abundant peak, and then there is a rapid drop off in signal down to cluster sizes $n=13$. In the protonated methanol-single water cluster series $\left(\left(\mathrm{CH}_{3} \mathrm{OH}\right)_{n}\left(\mathrm{H}_{2} \mathrm{O}\right) \mathrm{H}^{+}\right)$only cluster sizes $\mathrm{n}=4-12$ are seen with any intensity (Fig. $3 \mathrm{~b}$ ). Increase of the photon energy to $12 \mathrm{eV}$ shifts the intensity of the protonated clusters to $\left(\mathrm{CH}_{3} \mathrm{OH}\right)_{3} \mathrm{H}^{+}$and is followed then by a smooth decrease in intensity up to $n=13$ (shown in Fig. $3 \mathrm{c}$ ). There is a much larger change in the methanol-single water cluster series $\left(\left(\mathrm{CH}_{3} \mathrm{OH}\right)_{\mathrm{n}}\left(\mathrm{H}_{2} \mathrm{O}\right) \mathrm{H}^{+}\right)$upon increasing the photon energy (Fig. $\left.3 \mathrm{~d}\right)$. There is enhanced intensity for clusters $n=8$ and 9 and mixed water clusters are seen between $n=2-12$. The nature of these enhancements and their dependence on water concentration will be discussed below.

The appearance of protonated methanol upon ionization has been observed previously in a number of studies involving electron impact ${ }^{5}$, multiphoton ${ }^{3,4,28}$ and single photon ionization. ${ }^{10,17,18}$ It is believed that the ionization of the neutral hydrogen bonded clusters leads to the formation of the protonated cluster ions via rapid proton transfer and fragmentation. The distribution of protonated cluster ions seen in this work (Fig. 3 c) is very similar to that observed utilizing multiphoton ${ }^{4}$ ionization, $10.5^{17}$ and $26.5^{18} \mathrm{eV}$ single photon ionization. Previous photoionization studies at $10.5 \mathrm{eV}$ show that the protonated trimer is stronger in intensity compared to the dimer. ${ }^{10,17}$ It was speculated that the change in ion intensities between the dimer and trimer arose either due to different photoionization cross-sections ${ }^{18}$ for these species or that there is a magic number enhancement in the tetramer neutral precursor ${ }^{10}$ appearing in the mass spectrum as the protonated trimer. In this work we used tunable VUV to measure 
photoionization efficiency curves for $\left(\mathrm{CH}_{3} \mathrm{OH}\right)_{2} \mathrm{H}^{+}$and $\left(\mathrm{CH}_{3} \mathrm{OH}\right)_{3} \mathrm{H}^{+}$and these are plotted for the photon energy range of 9-14.6 eV for a pure methanol cluster beam (Fig 4). At $10.5 \mathrm{eV}$ the ratio of protonated trimer to dimer intensity is about 7.3, and at around $14 \mathrm{eV}$ the curves cross over. This switching over of photoionization curves could explain the difference in results between the $10.5 \mathrm{eV}$ work ${ }^{9,10}$ and results seen with higher photon energies ${ }^{18}$ where the protonated dimer is more abundant than the trimer. This however, does not resolve the question of whether the observed ion distributions arise from magic number distributions or from an enhanced photoionization cross-section for the protonated trimer at lower photon energies. It is apparent that attempting to determine magic numbers solely from data collected at a single photon energy as attempted in earlier work does not reflect the complexity of how the photoionization cross section, fragmentation dynamics and populations change over an energy range.

\section{Mass Spectrometry of mixed methanol-water clusters}

In addition to the main protonated methanol series of clusters, a second much weaker series of methanol-water clusters with the formula $\left(\mathrm{CH}_{3} \mathrm{OH}\right)_{\mathrm{n}}\left(\mathrm{H}_{2} \mathrm{O}\right) \mathrm{H}^{+}$are observed in Fig 1. Interestingly Bernstein and co-workers did not observe this series with either $10.5^{17}$ or $26.5^{18} \mathrm{eV}$ single photon ionization. In our work, these clusters can be observed around $9.8 \mathrm{eV}$ (appearance energies are reported in Table 1) and the intensities increase with photon energy (Fig. 3 b and d). There is enhanced intensity for clusters $n=8$ and 9 in this series. This kind of behavior has been observed earlier in electron impact ionization of methanol and methanol-water clusters by Garvey et al. ${ }^{15}$ and Elshall et al. ${ }^{29}$ The enhanced intensity of $\left(\mathrm{CH}_{3} \mathrm{OH}\right)_{9}\left(\mathrm{H}_{2} \mathrm{O}\right) \mathrm{H}^{+}$was attributed to complete solvation of a core $\mathrm{H}_{3} \mathrm{O}^{+}$ion by nine methanol molecules surrounding it and leading to the maximum number of hydrogen bonds. ${ }^{30}$ The authors also suggested that an efficient proton 
transfer takes place from methanol to be incorporated into a fully solvated hydronium ion. Castleman and co-workers also observed the formation of mixed methanol-water clusters upon ionization of pure alcohol clusters using multiphoton ionization. ${ }^{3,4,28}$ Using reflectron mass spectrometry and collision studies of ion-molecule cluster reactions in a flow cell, they suggested that it is the elimination of dimethyl ether $\left(\left(\mathrm{CH}_{3}\right)_{2} \mathrm{O}\right)$ from protonated methanol clusters that leads to the mixed cluster formation:

$$
\left(\mathrm{CH}_{3} \mathrm{OH}\right)_{\mathrm{n}} \mathrm{H}^{+} \rightarrow\left(\mathrm{CH}_{3} \mathrm{OH}\right)_{\mathrm{n}-2}\left(\mathrm{H}_{2} \mathrm{O}\right) \mathrm{H}^{+}+\left(\mathrm{CH}_{3}\right)_{2} \mathrm{O} \text {. }
$$

It was also suggested that this reaction occurs for size $n \geq 9$, since the smallest cluster observed in the works of Garvey ${ }^{15}$ and Castleman and co-workers ${ }^{3,4,28}$ is $\left(\mathrm{CH}_{3} \mathrm{OH}\right)_{7}\left(\mathrm{H}_{2} \mathrm{O}\right) \mathrm{H}^{+}$. Morgan et al. ${ }^{28}$ suggest that this reaction does not occur for the smaller clusters since the formation of a methyl bound complex intermediate is not facile. Garvey and co-workers ${ }^{15}$ comment that the distribution of the mixed cluster ions arising from either neat alcohol or alcohol-water mixtures are quite similar, but do not show any experimental data that can be compared with our results. With the addition of more water in the mixture we observe an enhancement of the signal towards smaller clusters (n=2-7) (Fig. 3 d), however under our experimental conditions it is the 8 and 9-mer which dominates the mixed cluster series. At each photon energy used, the intensity of all mixed clusters increase with the addition of water, as shown in Fig. $3 \mathrm{~b}$ and $\mathrm{d}$.

The mixed cluster series could originate from two sources, fragmentation of pure methanol clusters, as originally suggested by Castleman ${ }^{3,4}$ and shown in eq. (1) and also from photoionization of a mixed methanol-water cluster as shown in eq. (2)

$$
\left(\mathrm{CH}_{3} \mathrm{OH}\right)_{\mathrm{n}}\left(\mathrm{H}_{2} \mathrm{O}\right)+\mathrm{h} v \rightarrow\left(\mathrm{CH}_{3} \mathrm{OH}\right)_{\mathrm{n}-1}\left(\mathrm{H}_{2} \mathrm{O}\right) \mathrm{H}^{+}+\mathrm{CH}_{3} \mathrm{O}+\mathrm{e}^{-}
$$


The appearance of the mixed cluster ions in the pure methanol expansion probably arises from scheme (1) and with the addition of water scheme (2) will play an increased role in the ion distributions. The appearance of the smaller mixed clusters $(n=2-6)$ with increased photon energy (compare Fig. $3 \mathrm{~b}$ and d) could arise from the ionization energy being higher for the smaller clusters. They could also arise from fragmentation of larger clusters upon increased photon energy. However, since the relative cluster ion distributions remain the same between 12 and 14 $\mathrm{eV}$ (not shown), this mechanism can be safely discounted in this energy range.

\section{Photoionization efficiency curves of methanol and methanol-water clusters}

A primary motivation of probing the photoionization dynamics of mixed methanol-water clusters with variable photon energy is to observe a shift in ionization when water becomes available for ionization at $12.6 \mathrm{eV}$. There is no dramatic shift in the intensities of peaks in the mass spectra with change in photon energy above $12.6 \mathrm{eV}$ apart from the detection of the water monomer. No pure water clusters are observed under our expansion conditions. Previous work from our group ${ }^{25}$ has shown that the ionization energy of water decreases upon clustering reaching an asymptotic limit of around $10.6 \mathrm{eV}$ for clusters of size $\mathrm{n}>20$. A similar analysis was performed on the mixed methanol-water clusters in this work. PIE curves were recorded for detectable masses in the range of 9 to $15 \mathrm{eV}$ for various methanol-water solutions. The PIE curves for a methanol vapor mole fraction of 0.72 are shown in Fig. 5 for the photon energy range of 9-11 eV. The left column of Fig. 5 shows the PIE curves for protonated methanol monomer and methanol clusters $\left(\left(\mathrm{CH}_{3} \mathrm{OH}\right)_{\mathrm{n}} \mathrm{H}^{+}\right)$for $\mathrm{n}=2-6$, and Fig. 5 (right column) shows curves for methanol $\left(\mathrm{CH}_{3} \mathrm{OH}^{+}\right)$and protonated methanol-water $\left(\left(\mathrm{CH}_{3} \mathrm{OH}\right)_{n}\left(\mathrm{H}_{2} \mathrm{O}\right) \mathrm{H}^{+}\right)$clusters for $\mathrm{n}=2-6$. The corresponding appearance energies are reported in Table 1 . All of the appearance energies of protonated methanol clusters for $\mathrm{n} \geq 3$ and protonated methanol with a water monomer 
clusters for $n \geq 4$ are in the range of 9.6 to $9.9 \mathrm{eV}$. The values of the appearance energy obtained in this work disagree with that of Cook et al. ${ }^{1}$ for clusters larger than the protonated monomer which are also shown in Table 1 for comparison.

The appearance energy values obtained for unprotonated methanol monomer, dimer and protonated monomer are $10.80 \pm 0.05,9.8 \pm 0.2$ and $10.2 \pm 0.1$, respectively. Cook et al. ${ }^{1}$ observe a PIE curve for $\mathrm{m} / \mathrm{z}=33$ (protonated monomer), with appearance energy of $10.2 \mathrm{eV}$ which correlates well to the value obtained in this work. They observe a similar shoulder between this appearance energy and the sudden rise around $10.8 \mathrm{eV}$. Cook et al. operated a continuous molecular beam of pure methanol with pressure between $13.3-26.7 \mathrm{kPa}$. In this work a seeded expansion of methanol-water vapor in Ar is used and the shoulder only becomes pronounced upon dilution of methanol with water. This suggests that addition of water perturbs the PIE curve in the threshold ionization region. In a coincidence study employing synchrotron radiation, ${ }^{22}$ the appearance energy of protonated methanol is reported to be $10.15 \pm 0.05 \mathrm{eV}$ and the unprotonated dimer is observed at $9.7 \pm 0.05 \mathrm{eV}$ which agrees well within reported errors with our values of $10.2 \pm 0.1 \mathrm{eV}$ and $9.8 \pm 0.2 \mathrm{eV}$ respectively. Tsai et al. ${ }^{24}$ and Lee et al. ${ }^{23}$ performed $a b$-initio calculations for the methanol dimer and report vertical ionization energies of $9.74 \mathrm{eV}$ and 10.18 eV respectively. Tomoda and Kimura ${ }^{21}$ measured the photoelectron spectrum of the methanol dimer using a stripping technique. Analysis of their spectrum shows an onset at $9.8 \mathrm{eV}$ followed by a sharp rise in intensity at $10.7 \mathrm{eV}$ peaking at $11.21 \mathrm{eV}$. Tsai et al. ${ }^{24}$ photoionized the $\mathrm{CD}_{3} \mathrm{OH}$ dimer utilizing tunable VUV radiation between 10.49 and $10.91 \mathrm{eV}$ and probed the reaction products by TOF mass spectrometry. A plot of the ratio of $\left(\mathrm{CD}_{3} \mathrm{OH}\right) \mathrm{H}^{+} /\left(\mathrm{CD}_{3} \mathrm{OH}\right) \mathrm{D}^{+}$vs. photon energy shows a dramatic enhancement of signal around $10.8 \mathrm{eV}$. This was rationalized by the authors $^{24}$ to mean that the rate of proton transfer from the hydroxyl part of the photoionized 
dimer $\left(\mathrm{CD}_{3} \mathrm{OH}\right)_{2}{ }^{+}$increases around this energy. We see a similar enhancement in signal in $\left(\mathrm{CH}_{3} \mathrm{OH}\right) \mathrm{H}^{+}$around $10.8 \mathrm{eV}$. This could arise from either better Frank-Condon factors between the neutral and ionized species or due to enhanced proton transfer rates as was suggested by Tsai et al. ${ }^{24}$ It appears that proton transfer might be giving rise to this enhancement as opposed to photoionization dynamics since this effect is pronounced with the addition of more water to the solution.

\section{Threshold effects on PIE's upon addition of water}

PIE curves similar to those shown in Fig. 5 were recorded for methanol vapor mole fraction of $0.99,0.94,0.90$, and 0.59 and are not shown here for brevity. The shapes of these curves did not change with the mixing ratio apart for two peaks associated with protonated methanol monomer $\left(\mathrm{CH}_{3} \mathrm{OH}\right) \mathrm{H}^{+}$and unprotonated methanol dimer $\left(\mathrm{CH}_{3} \mathrm{OH}\right)_{2}{ }^{+}$and these are shown in Fig. 6. The curves have been normalized to the signal of methanol monomer at $13 \mathrm{eV}$. For protonated methanol, the appearance energy is $10.2 \mathrm{eV}$, beyond which there is a gentle rise in intensity up to $10.8 \mathrm{eV}$ following which there is a rapid rise. With an increase in water content in the mixture, the portion of the spectrum between $10.2 \mathrm{eV}$ and $10.8 \mathrm{eV}$ rises up creating a shoulder between these two energies. Integrating the area in this shoulder between onset and 10.8 $\mathrm{eV}$ and plotting it against the mole fraction of methanol in vapor above the methanol-water mixture yields an inverse linear correlation which is plotted in the inset of Fig. 6 a. For $\left(\mathrm{CH}_{3} \mathrm{OH}\right)_{2}{ }^{+}$, the PIE curves shown in Fig. 6 b, also display a similar trend. The PIE curves rise very gently from an onset of $9.8 \mathrm{eV}$. With an increase in water contribution to the solution, the onset remains the same, but the shape changes with the slope becoming almost a plateau after the initial rise. To quantify the change in shape of the PIE curve, the area between 9.7 and $11.5 \mathrm{eV}$ is plotted in the inset with change in methanol concentration in vapor. The linear relationships seen 
in the insets of Fig 6 a, b suggest that water is contributing in a similar way to the formation of the protonated monomer and the unprotonated dimer.

With the addition of water, it is probable that in addition to the methanol dimer $\left(\mathrm{CH}_{3} \mathrm{OH}\right)_{2}$ there will also be mixed clusters of the form $\left(\mathrm{CH}_{3} \mathrm{OH}\right)_{\mathrm{n}}\left(\mathrm{H}_{2} \mathrm{O}\right)_{\mathrm{m}}$ present in the molecular beam. Ionization and proton transfer from this species could also give rise to protonated methanol which could give rise to the increase in signal between threshold and 10.8 $\mathrm{eV}$ seen with increase in water concentration in the molecular beam. However, a thermodynamic analysis involving the following cycle for a methanol-water dimer

$$
\mathrm{AP}\left(\mathrm{CH}_{3} \mathrm{OH}\right) \mathrm{H}^{+}=\mathrm{D}\left(\mathrm{CH}_{3} \mathrm{OH}-\mathrm{H}_{2} \mathrm{O}\right)+\mathrm{D}(\mathrm{H}-\mathrm{OH})+\mathrm{IE}(\mathrm{H})-\mathrm{PA}\left(\mathrm{CH}_{3} \mathrm{OH}\right)
$$

$\mathrm{D}\left(\mathrm{CH}_{3} \mathrm{OH}-\mathrm{H}_{2} \mathrm{O}\right)^{31}=0.22 \mathrm{eV} ; \mathrm{D}(\mathrm{H}-\mathrm{OH})^{32}=5.1 \mathrm{eV} ; \mathrm{IE}(\mathrm{H})^{33}=13.598 \mathrm{eV} ; \mathrm{PA}\left(\mathrm{CH}_{3} \mathrm{OH}\right)^{33}=7.82$ $\mathrm{eV} ;(\mathrm{D}=$ dissociation energy; $\mathrm{IE}=$ ionization energy; $\mathrm{PA}=$ proton affinity $)$ suggests that the appearance energy of protonated methanol from a $\left(\mathrm{CH}_{3} \mathrm{OH}\right)\left(\mathrm{H}_{2} \mathrm{O}\right)$ dimer requires at least $11.1 \mathrm{eV}$ for the reaction to proceed. We cannot evaluate proton transfer from the methanol to water in this scheme since that would give rise to $\mathrm{CH}_{3} \mathrm{OH}^{+}$and the thermodynamic cycle would not be complete. However, a similar analysis for $\left(\mathrm{CH}_{3} \mathrm{OH}\right)_{2}$ with $\mathrm{D}\left(\mathrm{CH}_{3} \mathrm{OH}-\right.$ $\left.\mathrm{CH}_{3} \mathrm{OH}\right)^{1}=0.2 \mathrm{eV} ; \mathrm{D}\left(\mathrm{H}-\mathrm{OCH}_{3}\right)^{24}=4.51 \mathrm{eV} ; \mathrm{D}\left(\mathrm{H}-\mathrm{CH}_{2} \mathrm{OH}\right)^{24}=4.08 \mathrm{eV} ; \mathrm{IE}(\mathrm{H})^{33}=13.598 \mathrm{eV}$; $\mathrm{PA}\left(\mathrm{CH}_{3} \mathrm{OH}\right)^{33}=7.82 \mathrm{eV}$, predicts appearance energies of $10.06 \mathrm{eV}$ and $10.49 \mathrm{eV}$, for proton transfer from the methyl and hydroxyl group, respectively. Tsai et al. ${ }^{34}$ using ab-initio methods have calculated the various dissociation pathways possible upon ionization of a neutral methanol dimer $\left(\mathrm{CD}_{3} \mathrm{OH}\right)_{2}$. According to their calculations performed at the B3LYP level with zero-point vibrational energy corrections, to form $\mathrm{CD}_{3} \mathrm{O}+\mathrm{CD}_{3} \mathrm{OH}_{2}^{+}$or $\mathrm{CD}_{2} \mathrm{OH}+\mathrm{CD}_{3} \mathrm{OHD}^{+}$requires 10.37 $\mathrm{eV}$ and $10.08 \mathrm{eV}$ respectively. Comparing these predicted appearance energies to our results would suggest that at threshold the ionized dimer fragments to $\left(\mathrm{CH}_{3} \mathrm{OH}\right) \mathrm{H}^{+}+\mathrm{CH}_{3} \mathrm{O}$ and with 
increasing photon energy the second channel leading to $\left(\mathrm{CH}_{3} \mathrm{OH}\right) \mathrm{H}^{+}+\mathrm{CH}_{2} \mathrm{OH}$ comes into play. While this analysis provides a reasonable explanation for the shape of the protonated monomer PIE, it still does not explain the increase in intensity at threshold upon addition of water.

It is possible that $\left(\mathrm{CH}_{3} \mathrm{OH}\right)_{2}\left(\mathrm{H}_{2} \mathrm{O}\right)$ could give rise to the observed trends upon photoionization.

$$
\begin{aligned}
& \left(\mathrm{CH}_{3} \mathrm{OH}\right)_{2}\left(\mathrm{H}_{2} \mathrm{O}\right)+\mathrm{h} v \rightarrow\left(\mathrm{CH}_{3} \mathrm{OH}\right)_{2}{ }^{+}+\mathrm{H}_{2} \mathrm{O}+\mathrm{e}^{-} \\
& \left(\mathrm{CH}_{3} \mathrm{OH}\right)_{2}\left(\mathrm{H}_{2} \mathrm{O}\right)+\mathrm{h} v \rightarrow\left(\mathrm{CH}_{3} \mathrm{OH}\right) \mathrm{H}^{+}+\mathrm{CH}_{3} \mathrm{O}+\mathrm{H}_{2} \mathrm{O}+\mathrm{e}^{-}
\end{aligned}
$$

To the best of our knowledge, there are no experimental measurements of the dissociation energy of a water monomer from a methanol dimer in the neutral state to guide us in formulating a thermodynamic cycle as was done for methanol dimer and the methanol-water dimer in the previous paragraph. However, using the appearance energies observed in this work, we can calculate an approximate strength of the dissociation energy, for separating $\mathrm{H}_{2} \mathrm{O}$ and $\left(\mathrm{CH}_{3} \mathrm{OH}\right)_{2}$. The appearance energy (ionization energy) for $\left(\mathrm{CH}_{3} \mathrm{OH}\right)_{2}{ }^{+}$is $9.8 \mathrm{eV}$, the water contribution to the signal starts at $10 \mathrm{eV}$ photon energy (Fig $6 \mathrm{~b}$ ). This would suggest that the bond dissociation energy is at least $0.2 \mathrm{eV}$. In the previous paragraph we predict appearance energies of $10.06 \mathrm{eV}$ for $\left(\mathrm{CH}_{3} \mathrm{OH}\right) \mathrm{H}^{+}$formation from the methanol dimer $\left(\left(\mathrm{CH}_{3} \mathrm{OH}\right)_{2}\right)$. For equation (5), the bond dissociation energy between water and the methanol dimer will be the difference in the appearance energies of $\left(\mathrm{CH}_{3} \mathrm{OH}\right) \mathrm{H}^{+}$and the water dependent ion signal contribution which shows up at $10.2 \mathrm{eV}$ in Fig 6 (a). This would suggest a bond dissociation energy of at least 0.14 $\mathrm{eV}$ in equation (5). While the derivations are necessarily crude, the energies are typical of the strength of hydrogen bonds calculated in water methanol cluster systems. ${ }^{35-38}$ 
With the addition of water in the solution it is plausible that a water monomer will bind with a methanol dimer, the driving force would be the enhanced stability of a cyclic tetramer where three hydrogen bonds can form. Masella and Flament ${ }^{35}$ discuss the stability of these trimer species using ab-initio calculations. They find that while $\left(\mathrm{CH}_{3} \mathrm{OH}\right)_{3}$ is the most stable species, the $\left(\mathrm{CH}_{3} \mathrm{OH}\right)_{2}\left(\mathrm{H}_{2} \mathrm{O}\right)$ cluster is more stable than either $\left(\mathrm{CH}_{3} \mathrm{OH}\right)\left(\mathrm{H}_{2} \mathrm{O}\right)_{2}$ and $\left(\mathrm{H}_{2} \mathrm{O}\right)_{3}$. It is also suggested that cooperative effects strongly stabilize the cyclic trimers when compared to the isolated dimers. Using a localized orbital theory approach, hydrogen bonds are the result of charge transfer from a lone pair of the donor ( $\mathrm{sp}^{3}$ orbital) to an antibonding $\sigma^{*}$ orbital of the acceptor and this is reinforced in a cyclic cluster. Very recently, Mejia et al. ${ }^{37}$ performed a theoretical study to map out the potential energy surfaces of a number of alcohol-water trimers, among which $\left(\mathrm{CH}_{3} \mathrm{OH}\right)_{2}\left(\mathrm{H}_{2} \mathrm{O}\right)$ was also studied. They suggested that structures with a cyclic pattern in which all the three hydrogen bonds are in O-H---O configuration and simultaneously act as proton donors-acceptors are much more stable when compared to structures with just two primary hydrogen bonds. It is plausible that this strength in hydrogen bonding and increase in binding energies will increase the population of the methanol-water trimer with addition of water to the system. It is also important to point out that this is a fairly minor channel which could give rise to intensity at $\mathrm{m} / \mathrm{z}=33$ and 64 at threshold. The bulk of the signal in the PIE curves for $\mathrm{m} / \mathrm{z}$ $=33$ and 64 will arise from photoionization of the neutral dimer $\left(\mathrm{CH}_{3} \mathrm{OH}\right)_{2}$. We had remarked earlier that Cook et al. ${ }^{1}$ observed a shoulder in the PIE at threshold for the protonated monomer followed by a sharp rise at $10.8 \mathrm{eV}$. Our results show that this shoulder depends very strongly on the water content of the molecular beam and might suggest that the shape of the PIE curve observed in the work of Cook et al. ${ }^{1}$ could be explained by water being present in their methanol molecular beam. 
The decrease in the ionization energy between $\mathrm{CH}_{3} \mathrm{OH}$ and $\left(\mathrm{CH}_{3} \mathrm{OH}\right)_{2}$ is a general trend which is observed in hydrogen bonded systems (e.g. water, ammonia). Hydrogen bonding will cause a large destabilization of the highest occupied molecular orbital localized on the proton donor side. An examination of Table 1 shows that the most prominent change in ionization energy occurs when one moves from the monomer to the dimer. As remarked earlier, there are extreme geometry changes between the neutral and ionized clusters of methanol, which lead to subsequent proton transfer and fragmentation of the cluster. In our work with water clusters, ${ }^{25}$ we observed similar fragmentation and $\mathrm{OH}$ elimination from the cluster. By carefully measuring these fragmentation properties using reflectron mass spectrometry, we were able to correlate the appearance energies to ionization energies of the neutral cluster. However, in this work, the fragmentation properties could not be studied in detail since metastable peak signals were really low. Futhermore, the difference in proton transfer mechanisms of the two different hydrogens in methanol, e.g. the hydrogens bonded to the methyl group and to oxygen makes the ionization of methanol different from water, where there are two equivalent hydrogens. Hence we cannot derive ionization energies of the neutral precursors of the corresponding parent. However, qualitatively it is apparent that the appearance energies of the higher clusters do not change dramatically beyond the protonated dimer suggesting that added methanol or water do not affect the ionization dynamics profoundly.

\section{Conclusion}

In this work we report on the study of VUV photoionization of small methanol and methanolwater clusters. Protonated methanol clusters of the form $\left(\mathrm{CH}_{3} \mathrm{OH}\right)_{n} \mathrm{H}^{+}(\mathrm{n}=1-12)$ dominate the mass spectrum below the ionization threshold of the methanol monomer. With an increase in water concentration, small amounts of mixed clusters of the form $\left(\mathrm{CH}_{3} \mathrm{OH}\right)_{n}\left(\mathrm{H}_{2} \mathrm{O}\right) \mathrm{H}^{+}(\mathrm{n}=2-11)$ 
are detected. There is also some contribution to the mixed cluster signal from ion-molecule reactions within ionized pure methanol clusters. The enhanced intensity seen for $\left(\mathrm{CH}_{3} \mathrm{OH}\right)_{3} \mathrm{H}^{+}$ relative to $\left(\mathrm{CH}_{3} \mathrm{OH}\right)_{2} \mathrm{H}^{+}$at low photon energies is due to photoionization cross sections and not due to an apparent magic number in the neutral cluster distribution. The only unprotonated species observed in this work are the methanol monomer and dimer. Appearance energies are obtained by evaluating photoionization efficiency curves for $\mathrm{CH}_{3} \mathrm{OH}^{+},\left(\mathrm{CH}_{3} \mathrm{OH}\right)_{2}{ }^{+},\left(\mathrm{CH}_{3} \mathrm{OH}\right)_{\mathrm{n}} \mathrm{H}^{+}$ $(n=1-9)$ and $\left(\mathrm{CH}_{3} \mathrm{OH}\right)_{n}\left(\mathrm{H}_{2} \mathrm{O}\right) \mathrm{H}^{+}(\mathrm{n}=2-9)$ as a function of photon energy. The appearance energy of $10.2 \pm 0.1 \mathrm{eV}$ and $9.8 \pm 0.2 \mathrm{eV}$ for $\left(\mathrm{CH}_{3} \mathrm{OH}\right) \mathrm{H}^{+}$and $\left(\mathrm{CH}_{3} \mathrm{OH}\right)_{2}{ }^{+}$respectively agree very well with literature values. With an increase in the water content in the molecular beam, there is substantial enhancement of photoionization intensity for protonated methanol monomer and unprotonated methanol dimer at threshold. This may be explained by enhanced formation of a cyclic trimer containing two methanol molecules and a water monomer connected via three hydrogen bonds.

\section{Acknowledgements}

This work was supported by the Director, Office of Energy Research, Office of Basic Energy Sciences, Chemical Sciences Division of the U.S. Department of Energy under contract No. DE-AC02-05CH11231. 


\section{References}

(1) Cook, K. D.; Jones, G. G.; Taylor, J. W. Int. J. Mass Spectrom. Ion Processes 1980, 35, 273.

(2) Kebarle, P.; Haynes, R. N.; Collins, J. G. J. Am. Chem. Soc. 1967, 89, 5753.

(3) Morgan, S.; Castleman, A. W. J. Phys. Chem. 1989, 93, 4544.

(4) Morgan, S.; Keesee, R. G.; Castleman, A. W. J. Am. Chem. Soc. 1989, 111, 3841.

(5) Vaidyanathan, G.; Coolbaugh, M. T.; Garvey, J. F. J. Phys. Chem. 1992, 96, 1589.

(6) Stace, A. J.; Shukla, A. K. J. Am. Chem. Soc. 1982, 104, 5314.

(7) Nishi, N.; Yamamoto, K. J. Am. Chem. Soc. 1987, 109, 7353.

(8) Yang, S. F.; Brereton, S. M.; Ellis, A. M. Int. J. Mass Spectrom. 2006, 253, 79.

(9) Hu, Y. J.; Fu, H. B.; Bernstein, E. R. J. Chem. Phys. 2006, 125, 154306.

(10) Shi, Y. J.; Consta, S.; Das, A. K.; Mallik, B.; Lacey, D.; Lipson, R. H. J. Chem. Phys. 2002, 116, 6990.

(11) Remacle, F.; Levine, R. D. J. Chem. Phys. 2006, 125, 133321.

(12) Woon, D. E. Adv. Space Res. 2004, 33, 44.

(13) Raina, G.; Kulkarni, G. U. Chem. Phys. Lett. 2001, 337, 269.

(14) Short, L. C.; Cai, S. S.; Syage, J. A. J. Am. Soc. Mass Spectrom. 2007, 18, 589.

(15) Garvey, J. F.; Herron, W. J.; Vaidyanathan, G. Chem. Rev. 1994, 94, 1999.

(16) Shi, Z.; Wei, S.; Ford, J. V.; Castleman, A. W. Chem. Phys. Lett. 1992, 200, 142.

(17) Fu, H. B.; Hu, Y. J.; Bernstein, E. R. J. Chem. Phys. 2006, 124, 024302.

(18) Dong, F.; Heinbuch, S.; Rocca, J. J.; Bernstein, E. R. J. Chem. Phys. 2006, 124, 224319.

(19) Wakisaka, A.; Abdoul-Carime, H.; Yamamoto, Y.; Kiyozumi, Y. J. Chem. Soc. Faraday Trans. 1998, 94, 369. 
(20) Booze, J. A.; Baer, T. J. Chem. Phys. 1992, 96, 5541.

(21) Tomoda, S.; Kimura, K. Chem. Phys. 1983, 74, 121.

(22) Martrenchard-Barra, S.; Gregoire, G.; Dedonder-Lardeux, C.; Jouvet, C.; Solgadi, D.

PhysChemComm 1999, 4, 15.

(23) Lee, S. Y.; Shin, D. N.; Cho, S. G.; Jung, K. H.; Jung, K. W. J. Mass Spectrom. 1995, 30, 969.

(24) Tsai, S. T.; Jiang, J. C.; Lee, Y. T.; Kung, A. H.; Lin, S. H.; Ni, C. K. J. Chem. Phys. 1999, 111, 3434.

(25) Belau, L.; Wilson, K. R.; Leone, S. R.; Ahmed, M. J. Phys. Chem. A 2007, 111, 10075.

(26) Raina, G.; Kulkarni, G. U.; Rao, C. N. R. J. Phys. Chem. A 2001, 105, 10204.

(27) McGlashan, M. L.; Williamson, A. G. J. Chem. Eng. Data 1976, 21, 196.

(28) Morgan, S.; Castleman, A. W. J. Am. Chem. Soc. 1987, 109, 2867.

(29) Elshall, M. S.; Marks, C.; Sieck, L. W.; Meotner, M. J. Phys. Chem. 1992, 96, 2045.

(30) Lyktey, M. M. Y.; DeLeon, R. L.; Shores, K. S.; Furlani, T. R.; Garvey, J. F. J. Phys. Chem. A 2000, 104, 5197.

(31) Kirschner, K. N.; Woods, R. J. J. Phys. Chem. A 2001, 105, 4150.

(32) Harich, S. A.; Hwang, D. W. H.; Yang, X. F.; Lin, J. J.; Yang, X. M.; Dixon, R. N. J. Chem. Phys. 2000, 113, 10073.

(33) http//www.webbook.nist.gov.

(34) Tsai, S. T.; Jiang, J. C.; Lin, M. F.; Lee, Y. T.; Ni, C. K. J. Chem. Phys. 2004, 120, 8979.

(35) Masella, M.; Flament, J. P. J. Chem. Phys. 1998, 108, 7141.

(36) Curtiss, L. A.; Blander, M. Chem. Rev. 1988, 88, 827. 
(37) Mejia, S. M.; Espinal, J. F.; Restrepo, A.; Mondragon, F. J. Phys. Chem. A 2007, 111, 8250.

(38) Fileti, E. E.; Chaudhuri, P.; Canuto, S. Chem. Phys. Lett. 2004, 400, 494. 
Table 1 Appearance energies for pure and protonated methanol and methanol-water clusters evaluated from photoionization efficiency curves.

\begin{tabular}{|c|c|c|}
\hline Ion & $\begin{array}{c}\text { Appearance energy, eV } \\
\text { (this work) }\end{array}$ & Literature values, eV \\
\hline $\mathrm{CH}_{3} \mathrm{OH}^{+}$ & $10.80 \pm 0.05$ & $10.84^{\mathrm{a}}, 10.84 \pm 0.01^{\mathrm{b}}$ \\
\hline$\left(\mathrm{CH}_{3} \mathrm{OH}\right)_{2}{ }^{+}$ & $9.8 \pm 0.2$ & $9.8^{\mathrm{c}}, 9.7 \pm 0.05^{\mathrm{d}}$ \\
\hline$\left(\mathrm{CH}_{3} \mathrm{OH}\right)^{+} \mathrm{H}^{+}$ & $10.2 \pm 0.1$ & $10.2^{\mathrm{a}}, 10.15 \pm 0.05^{\mathrm{d}}$ \\
\hline$\left(\mathrm{CH}_{3} \mathrm{OH}\right)_{2} \mathrm{H}^{+}$ & $10.1 \pm 0.1$ & $9.8^{\mathrm{a}}$ \\
\hline$\left(\mathrm{CH}_{3} \mathrm{OH}\right)_{3} \mathrm{H}^{+}$ & $9.8 \pm 0.1$ & $9.5^{\mathrm{a}}$ \\
\hline$\left(\mathrm{CH}_{3} \mathrm{OH}\right)_{4} \mathrm{H}^{+}$ & $9.8 \pm 0.1$ & \\
\hline$\left(\mathrm{CH}_{3} \mathrm{OH}\right)_{5} \mathrm{H}^{+}$ & $9.6 \pm 0.1$ & \\
\hline$\left(\mathrm{CH}_{3} \mathrm{OH}\right)_{6} \mathrm{H}^{+}$ & $9.6 \pm 0.1$ & \\
\hline$\left(\mathrm{CH}_{3} \mathrm{OH}\right)_{7} \mathrm{H}^{+}$ & $9.8 \pm 0.1$ & \\
\hline$\left(\mathrm{CH}_{3} \mathrm{OH}\right)_{8} \mathrm{H}^{+}$ & $9.7 \pm 0.1$ & \\
\hline$\left(\mathrm{CH}_{3} \mathrm{OH}\right)_{9} \mathrm{H}^{+}$ & $9.8 \pm 0.1$ & \\
\hline$\left(\mathrm{CH}_{3} \mathrm{OH}\right)_{2}\left(\mathrm{H}_{2} \mathrm{O}\right) \mathrm{H}^{+}$ & $10.1 \pm 0.2$ & \\
\hline$\left(\mathrm{CH}_{3} \mathrm{OH}\right)_{3}\left(\mathrm{H}_{2} \mathrm{O}\right) \mathrm{H}^{+}$ & $10.2 \pm 0.1$ & \\
\hline$\left(\mathrm{CH}_{3} \mathrm{OH}\right)_{4}\left(\mathrm{H}_{2} \mathrm{O}\right) \mathrm{H}^{+}$ & $9.8 \pm 0.1$ & \\
\hline$\left(\mathrm{CH}_{3} \mathrm{OH}\right)_{5}\left(\mathrm{H}_{2} \mathrm{O}\right) \mathrm{H}^{+}$ & $9.9 \pm 0.1$ & \\
\hline$\left(\mathrm{CH}_{3} \mathrm{OH}\right)_{6}\left(\mathrm{H}_{2} \mathrm{O}\right) \mathrm{H}^{+}$ & $9.9 \pm 0.1$ & \\
\hline$\left(\mathrm{CH}_{3} \mathrm{OH}\right)_{7}\left(\mathrm{H}_{2} \mathrm{O}\right) \mathrm{H}^{+}$ & $9.8 \pm 0.1$ & \\
\hline$\left(\mathrm{CH}_{3} \mathrm{OH}\right)_{8}\left(\mathrm{H}_{2} \mathrm{O}\right) \mathrm{H}^{+}$ & $9.7 \pm 0.1$ & \\
\hline$\left(\mathrm{CH}_{3} \mathrm{OH}\right)_{9}\left(\mathrm{H}_{2} \mathrm{O}\right) \mathrm{H}^{+}$ & $9.6 \pm 0.1$ & \\
\hline
\end{tabular}

a) Ref. 1, b) Ref. 33, c) Ref. 21, d) Ref. 22 


\section{Captions:}

Figure 1. Time-of-flight mass spectrum of 5:1 methanol-water solution corresponding to methanol vapor mole fraction of 0.90 . Ionization is performed with $11 \mathrm{eV}$ light. Starting from $\mathrm{m} / \mathrm{z}=60$, the ion intensity is increased by a factor of 40 . The filled circles $(\bullet)$ indicate peaks associated with protonated methanol cluster cations $\left(\left(\mathrm{CH}_{3} \mathrm{OH}\right)_{\mathrm{n}} \mathrm{H}^{+}\right)$, open circles $(\circ)$ denote protonated methanol-single water cluster cations $\left(\left(\mathrm{CH}_{3} \mathrm{OH}\right)_{n}\left(\mathrm{H}_{2} \mathrm{O}\right) \mathrm{H}^{+}\right)$. Additionally a peak corresponding to unprotonated methanol monomer $(\mathrm{m} / \mathrm{z}=32)$ is shown.

Figure 2. Intensity of $\mathrm{H}_{2} \mathrm{O}(\mathrm{m} / \mathrm{z}=18)$ normalized to intensity of methanol peak $(\mathrm{m} / \mathrm{z}=32)$ at $13 \mathrm{eV}$ for various methanol-water concentrations. The ratio of methanol to water solution by volume is indicated next to each symbol. Solid line represents a linear fit to the experimental data.

Figure 3. Ion intensities of protonated methanol and methanol-water clusters at various photon energies and methanol-water mixtures. Signals have been normalized to the intensity of $\left(\mathrm{CH}_{3} \mathrm{OH}\right)^{+}$at $12 \mathrm{eV}$. The mole fraction of methanol in vapor above methanol-water solution is shown in the inset of each figure. (a) $\left(\mathrm{CH}_{3} \mathrm{OH}\right)_{\mathrm{n}} \mathrm{H}^{+}$at $10.0 \mathrm{eV}$; (b) $\left(\mathrm{CH}_{3} \mathrm{OH}\right)_{\mathrm{n}}\left(\mathrm{H}_{2} \mathrm{O}\right) \mathrm{H}^{+}$at $10.0 \mathrm{eV}$; (c) $\left(\mathrm{CH}_{3} \mathrm{OH}\right)_{\mathrm{n}} \mathrm{H}^{+}$at $12.0 \mathrm{eV}$; (d) $\left(\mathrm{CH}_{3} \mathrm{OH}\right)_{\mathrm{n}}\left(\mathrm{H}_{2} \mathrm{O}\right) \mathrm{H}^{+}$at $12.0 \mathrm{eV}$.

Figure 4. Photoionization efficiency curves for protonated methanol dimer $(\mathrm{m} / \mathrm{z}=65)$ and trimer $(\mathrm{m} / \mathrm{z}=97)$.

Figure 5. PIE curves for various species formed in an expansion of 0.72 mole fraction of methanol in vapor above methanol-water solution. $\mathrm{M}$ denotes methanol $\left(\mathrm{CH}_{3} \mathrm{OH}\right)$. PIE curves for 
protonated methanol monomer and methanol clusters $\left(\left(\mathrm{CH}_{3} \mathrm{OH}\right)_{n} \mathrm{H}^{+}\right)$for size $\mathrm{n}=2-6$ are shown in the left column; PIE curves for methanol cation $\left(\mathrm{CH}_{3} \mathrm{OH}^{+}\right)$and methanol-water clusters $\left(\left(\mathrm{CH}_{3} \mathrm{OH}\right)_{n}\left(\mathrm{H}_{2} \mathrm{O}\right) \mathrm{H}^{+}\right)$for $\mathrm{n}=2-6$ are shown in the right column. Arrows show appearance energies. Additionally for $\left(\mathrm{CH}_{3} \mathrm{OH}\right)_{2}\left(\mathrm{H}_{2} \mathrm{O}\right) \mathrm{H}^{+}$a line representing linear fit to the experimental data is shown.

Figure 6. PIE curves for (a) protonated methanol $(\mathrm{m} / \mathrm{z}=33)$ and $(\mathrm{b})$ unprotonated methanol dimer $(\mathrm{m} / \mathrm{z}=64)$ at various methanol-water concentrations. Mole fractions of methanol in vapor above methanol-water solution are shown in labels. The dependencies of area of PIE peak (a) from 10.0 to $10.8 \mathrm{eV}$ and (b) from 9.7 to $11.5 \mathrm{eV}$ on the mole fraction of methanol in vapor are shown in inserts together with a linear fit. 


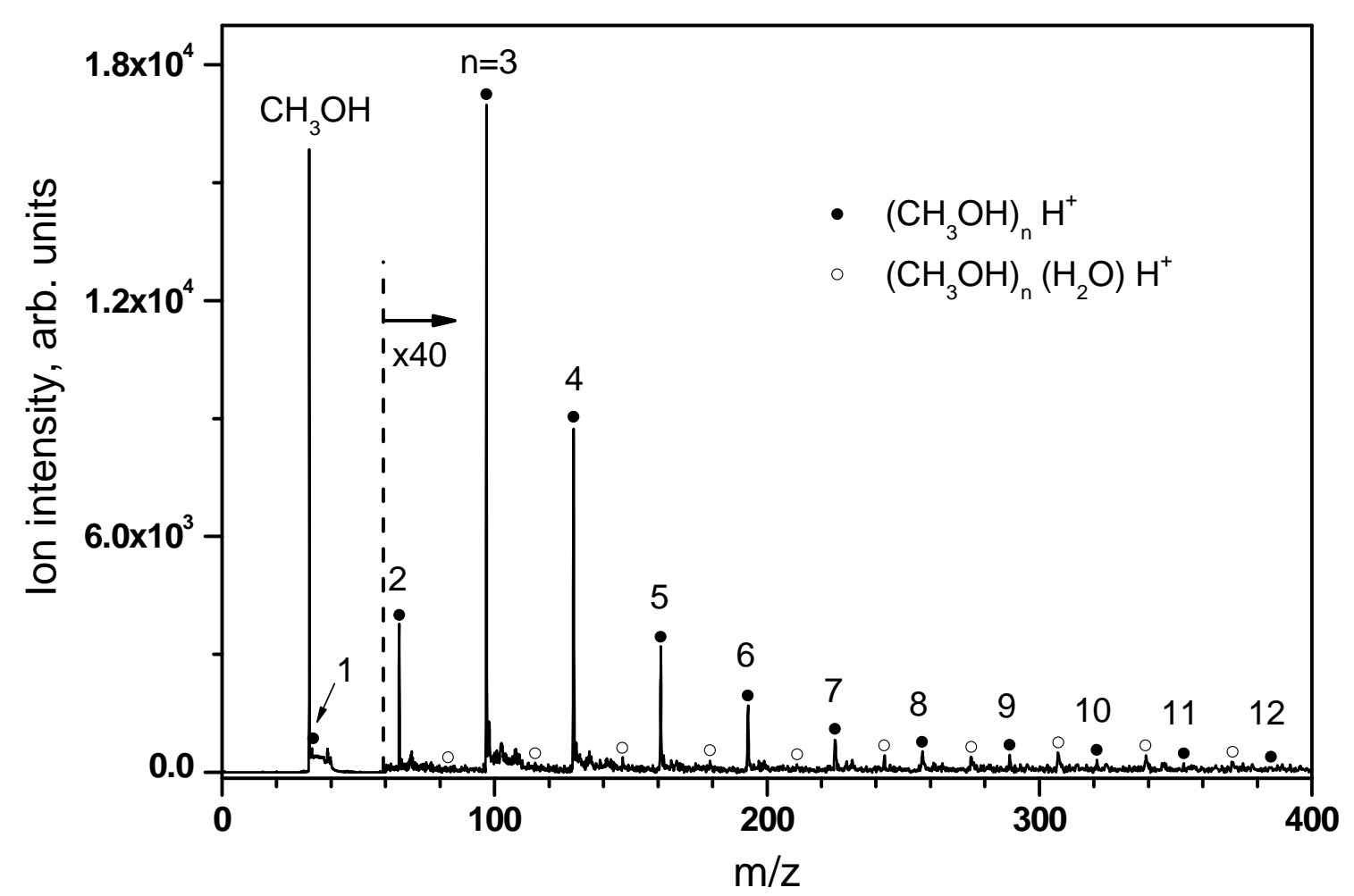

Figure 1. 


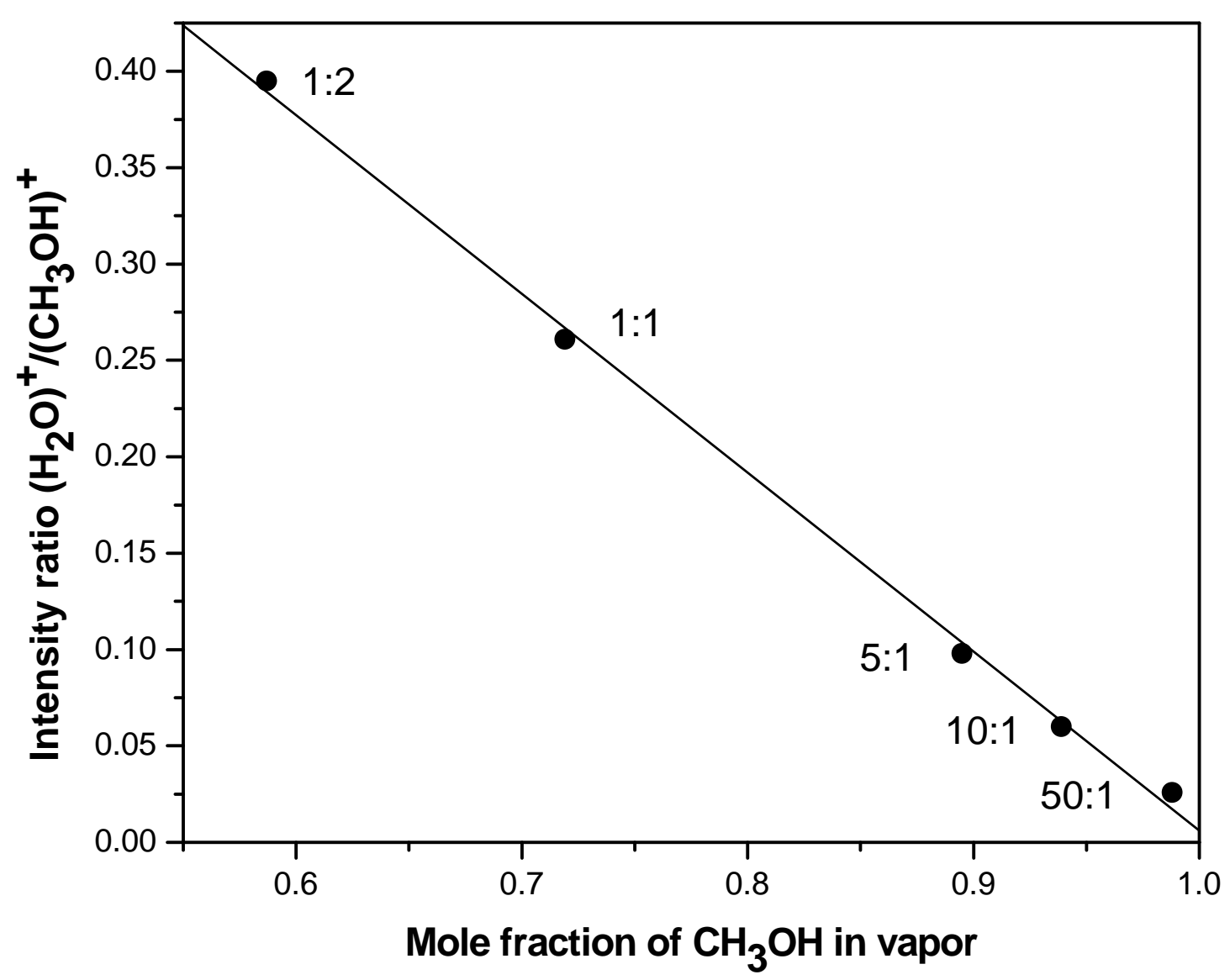

Figure 2 

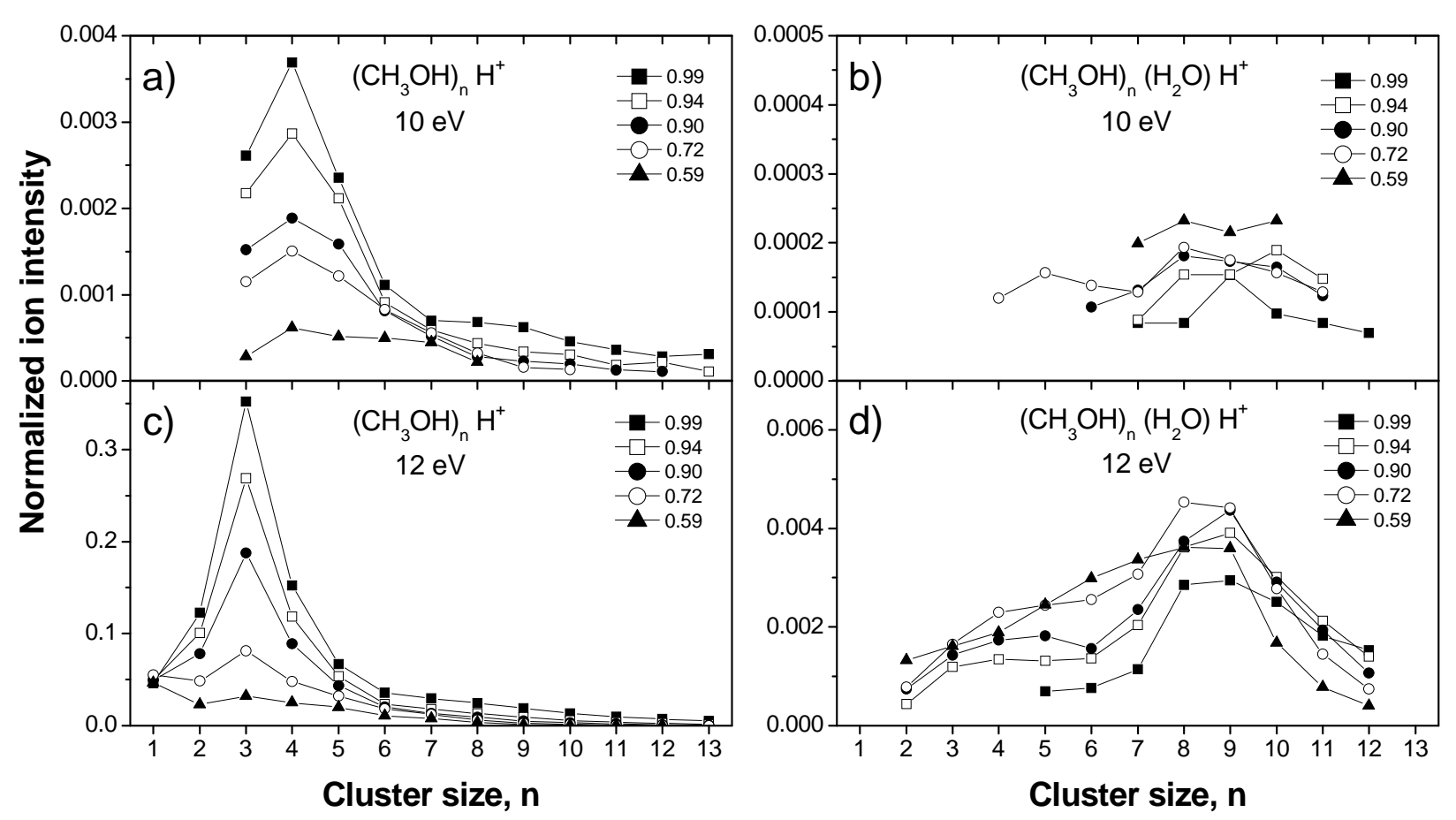

Figure 3 


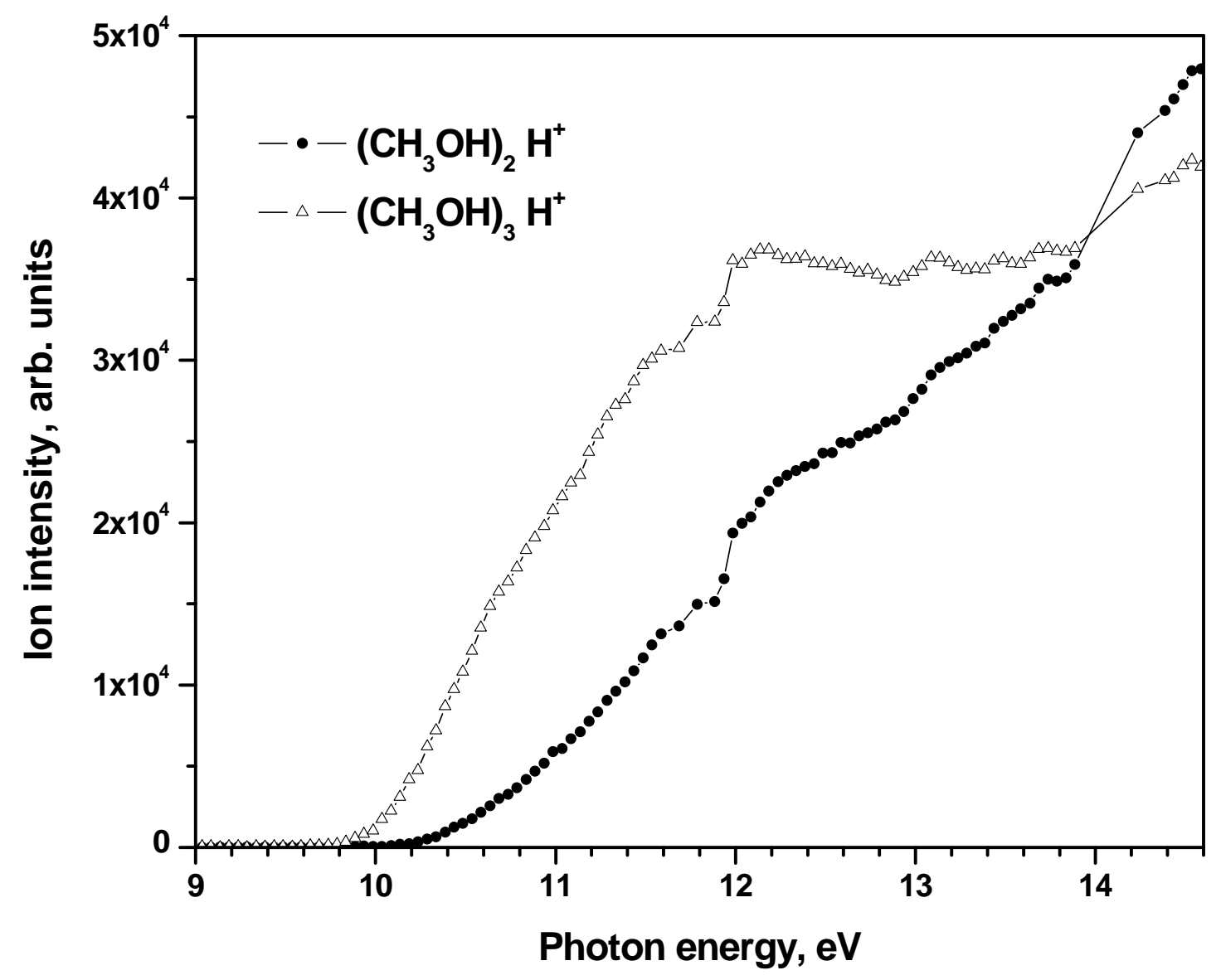

Figure 4 


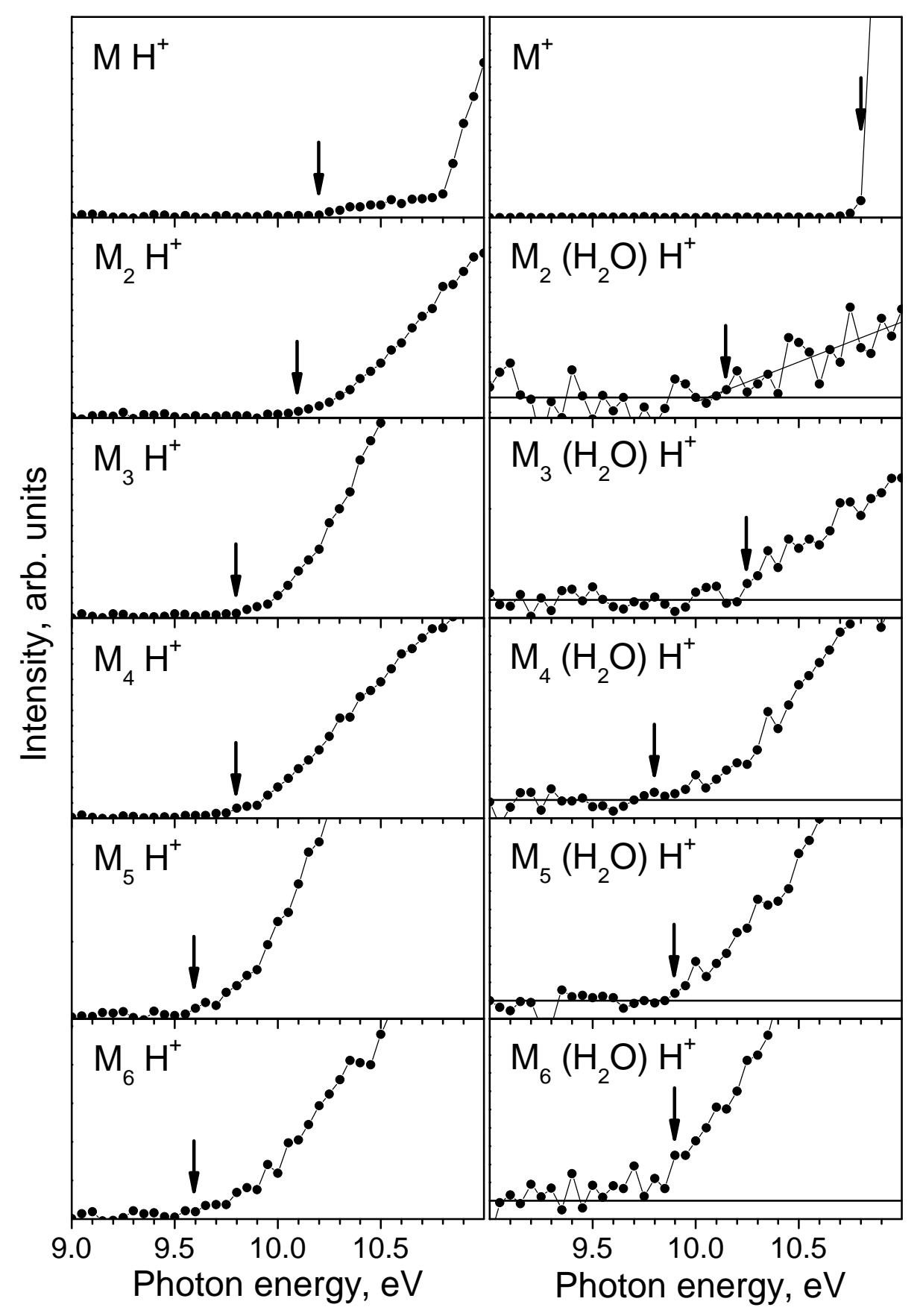

Figure 5 

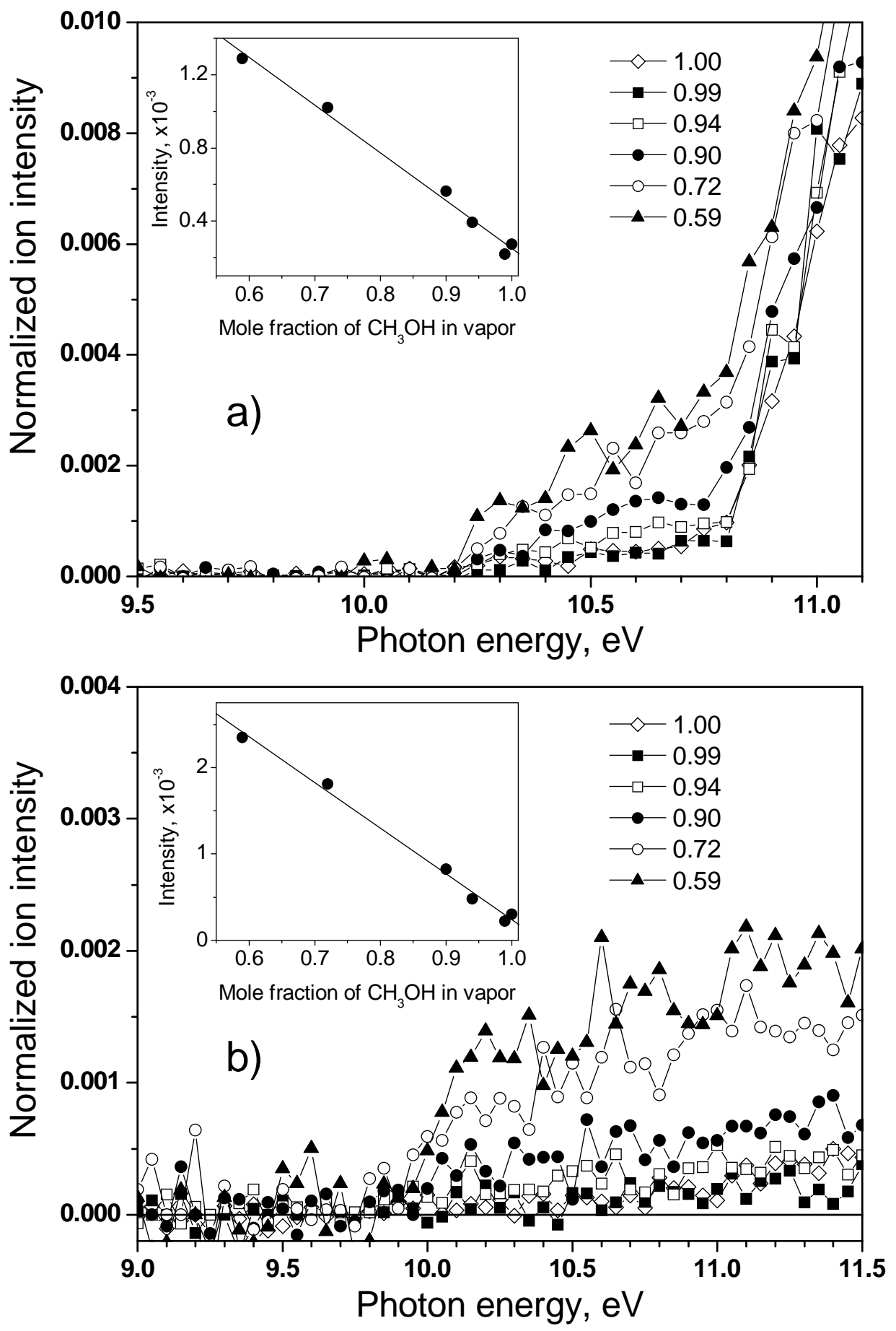

Figure 6 